\section{Influence of the Ultimate Torsion on the Geometry of Dental Implants}

Ana Beatriz V. Teixeira ${ }^{1}$, Gabriela B. S. P. Beja ${ }^{1}$, Antônio Carlos Shimano², Ana Paula Macedo ${ }^{1}$, Nathalia Ferraz Oliscovicz ${ }^{1}$, Andréa C. dos Reis ${ }^{1}$
'Ribeirão Preto Dental School, USP - University of São Paulo, Ribeirão Preto, SP, Brazil ${ }^{2}$ Ribeirão Preto Medical School, USP - University of São Paulo, Ribeirão Preto, SP, Brazil

Correspondence: Profa. Dra. Andréa Candido dos Reis, Avenida do Café, s/n, 14040-904 Ribeirão Preto, SP, Brasil. Tel: +55-16-3602-4044. e-mail: andreare73@yahoo.com.br

Key Words: dental implant, profile of dental implants, torsion test.
This study evaluated the profile of implants subjected to torsion test. Four types of implants (Conexão ${ }^{\oplus}$ ) were analyzed: Master Porous (MP - external hexagon, cylindrical, double-porous surface implants; $11.5 \times 3.75 \mathrm{~mm}$ ), Master Screw (MS - external hexagon, cylindrical, machined implants; $11.5 \times 3.75 \mathrm{~mm}$ ), Conect Conic (CC - external hexagon, cylindrical, machined implants; $11.5 \times 3.5 \mathrm{~mm}$ ) and Master Conect AR (CA - internal hexagon, cylindrical, double-porous surface implants; 11.5 X $3.75 \mathrm{~mm}$ ). The Nikon ${ }^{\oplus}$ model $\mathrm{C}$ profile projector was used for the analysis before and after torsion test with a Mackena model MK-20XX digital torque meter. The measures analyzed in the profile of implants were: diameter and height of the platform, diameter of the screw/platform connection, angle of the screw/platform connection, external diameter, internal diameter, thread pitch, height and length of the thread. Statistical analysis was performed using ANOVA and Tukey test at $5 \%$ significance level. The torsion test caused a visible deformity on the external implant profile. There was a statistical difference among the implants before and after torsion $(p<0.05)$ for the variables: platform diameter, platform height, diameter of the screw/ platform connection and length. Changes were observed in platform height of CC and CA, fracture of CA implants, fracture of the MP and MS assembler/connectors, and internal thread stripping of CC. Thus, it was concluded that excessive or some unadvised torque by the manufacturer can lead to changes in different geometric measurements of implants.

\section{Introduction}

Dental implants became consolidated after osseointegration was achieved by direct structural and functional connection between the bone and the implant surface $(1,2)$. However, maintenance is required to keep the integrity of the screw during placement and function. The bone/implant contact is related to surface treatment of the implants, which, in turn, aims to increase the surface area, facilitate bonding to the bone, and improve the biomechanical properties of the implant (3-5). Mechanical bonding features are provided by surface roughness, thus increasing the resistance to torque and bone-implant contact rate (4-6).

Implant primary stability, which consists in the resistance to movement immediately after insertion, is one of the factors that determine osseointegration and depends on various factors such as type of bone, shape, length, diameter and surface treatment of the screw, and type and number of threads (6-8). Choosing the thread geometry of the dental implant is an important factor to achieve good stability and initial osseointegration because it influences bone/implant contact, removal torque, strength of the implant to withstand mechanical and functional forces, and insertion (9).

The shape and prosthetic platform of the implant must be taken into consideration to avoid deformation of these elements after placement, since the shape and distribution of the threads also influence the torque load. Higher load torques during placement of the implant reduce the risk of micro-movements at the bone-implant interface, thereby obtaining a higher rate of success in implants with immediate loading $(10,11)$.

Implants can undergo internal and external morphological changes during torsion when inserted into the bone (12). The strength of titanium or a titanium alloy depends on its microstructure, which is influenced by its composition, heat treatment and the machining process (12). When placing the implant, the dentist may apply greater insertion torque than the maximum allowable load, which may cause fracture of the implant or the bone, depending on geometry and density. Accordingly, there is a need to know the influence of forces applied on implants on their physical and mechanical properties as well as predict and guide the best indication and use of implants to prevent damage to the bone and/or screw, and the consequent failure of rehabilitation. Even though implant or bone fracture may not occur, exceeding the amount of torque without knowing the limits of the physicomechanical properties of the screw, may lead to impairment of primary stability, loosening of the retaining screw, permanent deformation of the platform and cause damage to the internal threads, which hinders prosthetic rehabilitation $(11,13)$. Given the variability of effects that insertion torque can cause to the shape of implants, the 
aim of this study was to assess the possible profile changes in the implants after torsion test.

\section{Material and Methods}

Two previously marked sides of 20 titanium dental implants (Conexão Sistema de Prótese, Arujá, SP, Brazil) were divided into the following groups $(n=10)$ : Master Porous (MP - external hexagon, cylindrical, double-porous surface implants; 11.5 X $3.75 \mathrm{~mm}$ ), Master Screw (MS external hexagon, cylindrical, machined implants; $11.5 \mathrm{X}$ $3.75 \mathrm{~mm}$ ), Conect Conic (CC - external hexagon, cylindrical, machined implants; $11.5 \times 3.5 \mathrm{~mm}$ ) and Master Conect AR (CA - internal hexagon, cylindrical, double-porous surface implants; $11.5 \times 3.75 \mathrm{~mm}$ ).

The profile analysis of the implants was performed using the Profile Projector model 6C (Nikon ${ }^{\circledR}$ Corporation Instruments Company, Tokyo, Japan). The equipment allows the dimensional assessment of small parts with complex shapes by projecting an enlarged image of the part profile on a screen using objective lenses. For this study, the objective lenses were set at $20 \times$ magnification. The projection screen has a template with two perpendicular lines used as reference measurements and a combined coupled to micrometers to perform the measurements.

The implants were placed on the using rectangular wood device, manufactured in the workshop क्ष of the Department of Dental Materials and Prosthesis of the Dental School of Ribeirão Preto - USP, with a hole compatible with the connector on which the implant was coupled. This connector of implants that comes from the factory is used to insert it in the bone during surgery (Fig. 1). The profiles of the implants were traced with vegetable parchment so that the following items were examined: both sides of each implant, the number and homogeneity between the thread fillets (presence or absence of metal barbs), the thread profile of the implants and where the implant fracture occurred after the torsion test. The following measurements of the two previously marked sides of implants (Fig. 2) were analyzed with the micrometer: DP $=$ diameter of the implant platform; $\mathrm{HP}=$ height of the implant platform; $\mathrm{DPR}=$ diameter of platform connection; $\alpha-P=$ platform/thread angle of connection; $D E=$ external diameter; $\mathrm{DI}=$ internal diameter; $\mathrm{PR}=$ thread step; $\mathrm{HR}=$ thread pitch; and $\mathrm{C}=$ implant length. The $\alpha-P$ angle was obtained with the goniometer.

The arithmetic mean of three readings was calculated in order to prevent distortions in the results and then a general mean was calculated for each group of implants. All measurements were verified before and after the torsion test.

The torsion manual test was performed by a digital torque meter (Mackena ${ }^{\oplus}$, São Paulo, SP, Brazil) model MK20XX, with a maximum capacity of $10 \mathrm{~N} . \mathrm{m}$ and precision of $0.01 \mathrm{~N} . \mathrm{m}$ to quantify the torque applied to the implant at each rotation. To conduct this test, the screws were locked in a vise with the hexagon side facing up.

A hexagonal fitting part was fabricated in the precision workshop of the Campus of USP Ribeirão Preto, adapted to the sizes of the connector of external hexagon screw and also an accessory part that fits internally to the internal connection. Both the connector and the accessory were coupled to the torque meter.

This part was maintained at an angle of $90^{\circ}$ between the arm of the torque meter and the longitudinal axis of the screw. An examiner started a circular movement in a
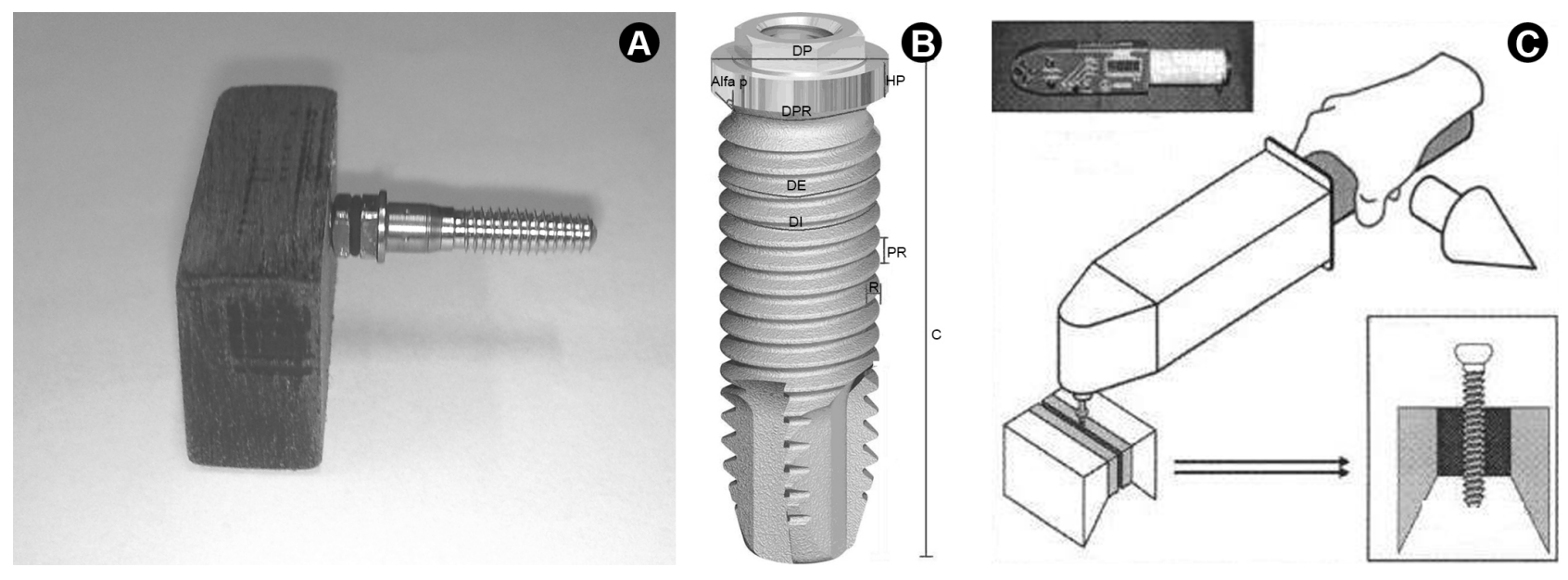

Figure 1. Wood device used to adapt the implant to the profile projector (A). Implant areas analyzed (B). Scheme of torsion test using the torque meter and vise (C). 
clockwise direction at a speed of 1-5 rotations/minute until torsion or rupture of the screw (Fig. 3).

Statistical analysis was performed by the KolmogorovSmirnov normality test. After determining normality, the ANOVA parametric test and Kruskal-Wallis non-parametric test were used at a significance level of 5\%. Tukey test was used to detect the differences among the means.

\section{Results}

CA showed the highest mean torque $(\mathrm{Nm})(1.498 \pm$ 0.327 ) until fracture occurred at the cutting height of the implant (where it was fixed in the vise). However, no statistically significant difference $(p=0.38)$ was found from groups MP and MS, which exhibited intermediate mean torques $(\mathrm{Nm})(1.298 \pm 0.294$ and $1.254 \pm 0.217$, respectively) and fractured at the connector. CC the lowest mean torque $(\mathrm{Nm})(0.544 \pm 0.089)$ with internal thread stripping when maximum torque was applied, differing significantly from the other groups $(p<0.05)$.

Statistical analysis was performed for the difference between the DP, HP, DPR and $C$ values obtained before and after torsion test. The other measurements $(\alpha-P$, $D E, D I, H R, P R$ ) were taken of the first threads below the implant platform. As the vise was adapted to the cutting height of the implant, no major changes were found in the measurements before and after the torsion test (Table 1).

No statistically significant difference was found between the DP and DPR groups ( $p=0.451$ and $p=0.062$, respectively) for implant size, and a statistically significant difference was found between groups $C C$ and $C A(p=0.027)$ for HP size. The $C$ size of MP, MS and CC groups did not show any statistically significant difference $(p=0.358)$.

The implant fracture site in each group was as follows: $\mathrm{MP}$ and MS, intermediate abutment screw; $\mathrm{CC}$, internal thread stripping of the implant; and $C A$, cutting height of the implant.

\section{Discussion}

The great relevance of this study is to show in detail the influence of forces applied to implants on their physical and mechanical properties. It also aims to predict and guide the best indication and use of these implants to prevent damage to the bone and/or screw, preventing failure rehabilitation, in addition to bringing unprecedented comparisons in the literature. The groups before torsion were similar. When submitted to the torsion test, the dimensional analysis showed statistical similarity in the dimensions of the platform diameter and height, diameter of the platformthread connection and screw length, and difference in values before and after torsion in all groups of implants. The greatest deformation was observed in the part where the implant was fixed to the vise, and deformations in the long axis and high strength values were found.

With regards to the prosthetic platform, it was not possible to find deformations visible to the naked eye. However, when using the magnified view of the part, minor changes were found in CC and major changes in CA with statistical differences between these two groups. This result is relevant because the prosthetic platform is basic for the rehabilitation of implant stability and it should necessarily have no deformations in order to place and maintain the prostheses. This confirms the hypothesis of the authors that excess internal torque and excess torque in the prosthetic platform can change the primary stability of the implant and/or compromise the adjustment of the prosthetic component and produce future deformation.

With regards to the diameter and height of the platform, diameter of platform-thread connection and length of the screw, no visible deformation was found in MP, MS and CC, even when fixed to the vise and submitted to high levels of torque, indicating greater resistance of these screws, but the same was not found in a previous study for the Branemark implant type, which discusses cases of fracture during prosthetic rehabilitation (14).

The change in HP dimension between groups CC and CA suggests that, even subjected to the same torque, the larger deformation and greater impairment for future rehabilitation occurs in CC (external hexagon), a fact that

Table 1. Difference between measurements before and after torsion test expressed as mean \pm standard deviation $(\mu \mathrm{m})$

\begin{tabular}{|c|c|c|c|c|c|c|c|c|c|}
\hline Group & $\mathrm{DP}^{\mathrm{a}}$ & $\mathrm{HP}^{\mathrm{b}}$ & $\mathrm{DPR}^{\mathrm{a}}$ & $\mathrm{DE}$ & $\mathrm{Dl}$ & $\alpha-P$ & PR & $\mathrm{HR}$ & $\mathrm{Ca}^{\mathrm{a}}$ \\
\hline MP & $117 \pm 134^{*}$ & $98 \pm 98^{*, * *}$ & $130 \pm 74^{*}$ & $21 \pm 34$ & $78 \pm 121$ & $26 \pm 20$ & $904 \pm 236$ & $79 \pm 77$ & $12 \pm 14^{*}$ \\
\hline MS & $17 \pm 23^{*}$ & $120 \pm 173$ & $133 \pm 100^{*}$ & $17 \pm 23$ & $137 \pm 159$ & $19 \pm 17$ & $660 \pm 174$ & $75 \pm 74$ & $7 \pm 10^{*}$ \\
\hline $\mathrm{CC}$ & $71 \pm 148^{*}$ & $43 \pm 29^{*}$ & $95 \pm 97^{*}$ & $16 \pm 30$ & $168 \pm 190$ & -- & $56 \pm 69$ & $162 \pm 175$ & $8 \pm 9^{*}$ \\
\hline CA & $131 \pm 130^{*}$ & $137 \pm 76^{* *}$ & $67 \pm 89^{*}$ & $41 \pm 67$ & $76 \pm 154$ & $64 \pm 43$ & $109 \pm 148$ & $65 \pm 89$ & $138 \pm 66$ \\
\hline
\end{tabular}

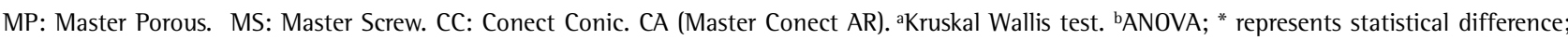
***epresents no statistically significant difference. $\mathrm{DP}=$ diameter of the implant platform; HP $=$ height of the implant platform; DPR $=$ diameter of platform connection; $\alpha-\mathrm{P}=$ platform/thread angle of connection; $\mathrm{DE}=$ external diameter; $\mathrm{Dl}=$ internal diameter; $\mathrm{PR}=$ thread step; $\mathrm{HR}=$ thread pitch; $\mathrm{C}=$ implant length. 
also involves the adaptation of the prosthetic component. It is known that external hexagon implants are indicated for mandibular protocols, where the bone is very dense and torque on these situations may be more frequent, leading to the general problem of mismatch among the prosthetic components (11). The tapered implant (CC) has a smaller diameter compared with other implants, which justifies its greater deformation and difference from group CA (internal hexagon); a fact not observed in MP and MS with statistical significance. This shows the importance of studying prosthetic platforms, diameter and shape of the screws, but further studies are required to determine what happens inside the screw when subjected to internal forces.

Although the values are similar, deformation occurs in the DPR because of stress concentration in the implant area, creating a cervical neck.

Although the $\mathrm{C}$ size of MP, MS and CC groups did not show any difference, Group 4 was not compared with the other groups because the fracture occurred after the torsion test. External hexagon implants placed with the use of connectors, with load directly applied to connection, are subject to deformations in the region of the hexagon when torque exceeds $55 \mathrm{~N} . \mathrm{cm}$ and are subject to complete hexagon thread stripping when torque is close to 70 N.cm. Thus, the connector may fracture first and cause deformation of the prosthetic platform (15).

Internal hexagon implants support torques around $80 \mathrm{~N} . \mathrm{cm}$ without deformation and rupture torque is over $150 \mathrm{~N} . \mathrm{cm}$. They present better mechanical performance (16) as they have micro-threads that increase the bone/ implant contact surface, which allows higher torque and increases primary stability. In addition, they prevent stress concentration making the implant more resistant to the mastication loads exerted on the prosthesis. This type of implant has no connector, so it is used as a key that transports and inserts the implant into the bone. This reduces surgical time and contamination during surgery, providing greater torque resistance and stability $(16,17)$. In this study, there was rupture of implant components (external hexagon) subjected to a $129.8 \mathrm{~N} . \mathrm{cm}$ torque and fracture of the internal hexagon implant screws subjected to a $149.8 \mathrm{~N} . \mathrm{cm}$ torque. The higher values of maximum torque force in $\mathrm{G} 4$ may be due to the greater internal area of the prosthetic connection screw.

Implant fracture occurs by undetected loosening that is aggravated by the non-axial movements during prosthetic loading. Fracture of the intermediate abutment screw may occur at the level of the upper hexagon portion, which was observed in groups MP and MS that showed fracture of the component (connector). This type of fracture has an advantage over the other groups because the fractured components can be easily removed. When the most apical portion breaks in the internal part of the implant, it is more difficult to remove the screw due to its proximity with the implant screw (18). After five-year follow-up of implant rehabilitation, Branemark (19) stated that the fracture of the screw of the prosthetic abutment is one of the most common problems. Rivaldo et al. (20) showed that implants with a diameter smaller than $3.75 \mathrm{~mm}$ present internal screw loosening that would probably fracture when masticatory loads are applied. These authors suggest that the industry should change the internal design of implants using smaller internal threads no larger than $1.37 \mathrm{~mm}$ in diameter and external diameter less than $1.91 \mathrm{~mm}$ or indicate these screws to rehabilitation cases requiring multiple implants and fixed prostheses.

The difference between this study and the clinical reality is that the apical base of the implant was fixated to the equipment that provided rigidity, particularly to assess what maximum force would be needed to hinder the implant system, if it would fracture along the axis, deform the platform, or deform the external and/or internal threads. In case of the internal hexagon implant, its larger internal area to connect the prosthesis increases tensile force transmission along the axis of the implant and facilitates fracture.

The tapered implant showed the lowest torsion values (54.4 N.cm) and thread stripping occurred in the internal threads because they were narrow, which facilitates deformation. This fact prevents greater dissipation of stress along the axis of the implant, hindering its use, since the deformation of these threads prevents the adjustment of the prosthesis or reduces durability and stability and recurrent adjustments are necessary. The $\alpha$-P angle of the tapered implant cannot be calculated using the profile projector because it has a curved finishing.

The results of the present study showed that the groups were homogeneous in their dimensions when available, i.e., before the torsion test. The manual torsion test influenced the height of the platform with statistically different results between $\mathrm{CC}$ and $\mathrm{CA}$. In the analysis before and after the torsion test, differences in the height of the prosthetic platform and the diameter of the platform connection were found. The screw in group CA and the connectors in groups MP and MS fractured when torsional forces were applied.

\section{Resumo}

Este estudo avaliou o perfil de implantes submetidos à torção. Foram analisados quatro tipos de implantes (Conexão ${ }^{\circledR}$ ): Master Porous (MP - implantes cilindricos com encaixe hexagonal externo e superfície duplamente porosa; 11,5 X 3,75 mm), Master Screw (MS - implantes cilindricos com encaixe hexagonal externo e superficie usinada; 11,5 $X$ 3,75 mm), Conect Conic (CC - implantes cilindricos com encaixe hexagonal externo e superficie usinada; $11,5 \times 3,5 \mathrm{~mm}$ ) e Master Conect AR (CA - implantes cilindricos com encaixe hexagonal externo e superfície duplamente porosa). Utilizou-se para a análise o projetor de 
perfil Nikon ${ }^{\circledR}$ modelo C, antes e após o ensaio de torção, com torquímetro digital Mackena ${ }^{\circledR}$ modelo MK-20XX. As medidas analisadas do perfil dos implantes foram: diâmetro da plataforma, altura da plataforma, diâmetro da conexão plataforma-rosca, ângulo da conexão plataforma-rosca, diâmetro externo, diâmetro interno, passo de rosca, altura da rosca e comprimento. Para obtenção dos resultados foi realizada análise estatística ANOVA e Teste de Tukey com 5\% de nivel de significância. 0 ensaio de torção causou deformação visivel no perfil externo dos implantes. Houve diferença estatística entre os implantes $(p<0,05)$, antes e após a torção, nas variáveis: diâmetro da plataforma, altura da plataforma, diâmetro da conexão plataforma-rosca e comprimento. Foram observadas alterações na altura da plataforma dos implantes $\mathrm{CC}$ e $\mathrm{CA}$, fratura dos implantes $\mathrm{CA}$, fratura do montador de MP e MS, e espanamento das roscas internas de CC. Portanto, os implantes são homogêneos antes da torção, porém esta influenciou no perfil desses quando excessiva, causando deformação do parafuso.

\section{References}

1. Brånemark $R$, Brånemark $P I$, Rydevik $B$, Myers RR. Osseointegration in skeletal reconstruction and rehabilitation: A review. J Rehabil Res Dev 2001;38:175-181.

2. Novaes Jr. AB, Souza SLS, Barros RRM, Pereira KKY, lezzi G, Piattelli A. Influence of implant surfaces on osseointegration. Braz Dent J 2010;21:471-481.

3. Cheng Z, Zhang F, He F, Zhang L, Guo C, Zhao S, et al.. Osseointegration of titanium implants with a roughened surface containing hydride ion in a rabbit model. Oral Surg Oral Med Oral Pathol Oral Radiol Endod 2010;110:e5-e12.

4. Ferguson SJ, Langhoff JD, Voelter K, Rechenberg B, Scharnweber D,

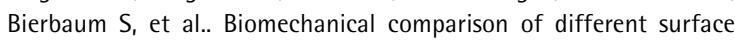
modifications for dental implants. Int J Oral Maxillofac Implants 2008;23:1037-1046

5. Barros RRM, Novaes Jr. AB, Papalexiou V, Souza SLS, Taba Jr. M, Palioto DB, et al.. Effect of biofunctionalized implant surface on osseointegration - A histomorphometric study in dogs. Braz Dent J 2009;20:91-98.

6. Shalabi MM, Gortemaker A, Van't Hof MA, Jansen JA, Creugers NHJ. Implant surface roughness and bone healing: a systematic review. J Dent Res 2006;85:496-500

7. Mesa $F$, Muñoz R, Noguerol B, de Dios Luna J, Galindo P, O'Valle F. Multivariate study of factors influencing primary dental implant stability. Clin Oral Implants Res 2008;19:196-200.
8. O'Sullivan D, Sennerby L, Meredith N. Measurements comparing the initial stability of five designs of dental implants: A human cadaver study. Clin Implant Dent Relat Res 2000;2:85-92.

9. Steigenga J, Al-Shammari K, Misch C, Nociti FHJR, Wang HL. Effects of implant thread geometry on percentage of osseointegration and resistance to reverse torque in the tibia of rabbits. J Periodontol 2004;75:1233-1241.

10. Trisi P, Perfetti G, Baldoni E, Berardi D, Colagiovanni M, Scogna G. Implant micromotion is related to peak insertion torque and bone density. Clin Oral Implants Res 2009;20:467-471.

11. Barbosa GAS, Simamoto Júnior PC, Fernandes Neto AJ, Mattos MGC, Neves FD. Prosthetic laboratory influence on the vertical misfit at the implant/UCLA abutment interface. Braz Dent J 2007;18:139-143.

12. lijima M, Muguruma T, Brantley WA, Okayama M, Yuasa T, Mizoguchid I. Torsional properties and microstructures of miniscrew implants. Am J Orthod Dentofacial Orthop 2008;134:333.e1-e6.

13. Glauser CR, Oden ZM, Ambrose CG, Willits MB, Coupe KJ. Mechanical testing of small fracture implants for comparison of insertion and failure torques. Arch Orthop Trauma Surg 2003;123:388-391.

14. Nergiz I, Schmage $P$, Shahin R. Removal of a fractured implant abutment screw: A clinical report. J Prosthet Dent 2004;91:513-517.

15. Constantino A. Osseocompression. Optimizing primary stability for immediate load in dental implants. Implant News 2004;1:219-226.

16. Soares MAD, Ciuccio RL, Filho AJ, Lenharo A, Luiz NE. Implant cone morse self-drilling implant with internal torque - Part I: product development. Innov Implant J Biomater Esthet 2006;1:63-69.

17. Arvidson $\mathrm{K}$, Bystedt $\mathrm{H}$, Frykholm A, Konow LV, Lothigius E. Five-years prospective follow-up report of the Astra Tech dental implant system in the treatment of edentulous mandible. Clin Oral Implants Res Berne 1998:4:225-234.

18. Zarb GA, Bolender CL, Hickey JC, Carlsson GE. Boucher's prosthodontic treatment for edentulous patients. 10th ed. St Louis: CV Mosby; 1990.

19. Branemark PI. Intra-osseous anchorage of dental prostheses. I. Experimental studies. Scand Plast Reconstr Surg 1969;3:81-100.

20. Rivaldo EG, Wutke C, Silveira M, Frasca LCF, Fernandes EL, Pocztaruk RL. Structural failure in full fixed denture implant retained: Case report. Stomatos 2007;13:131-138. 